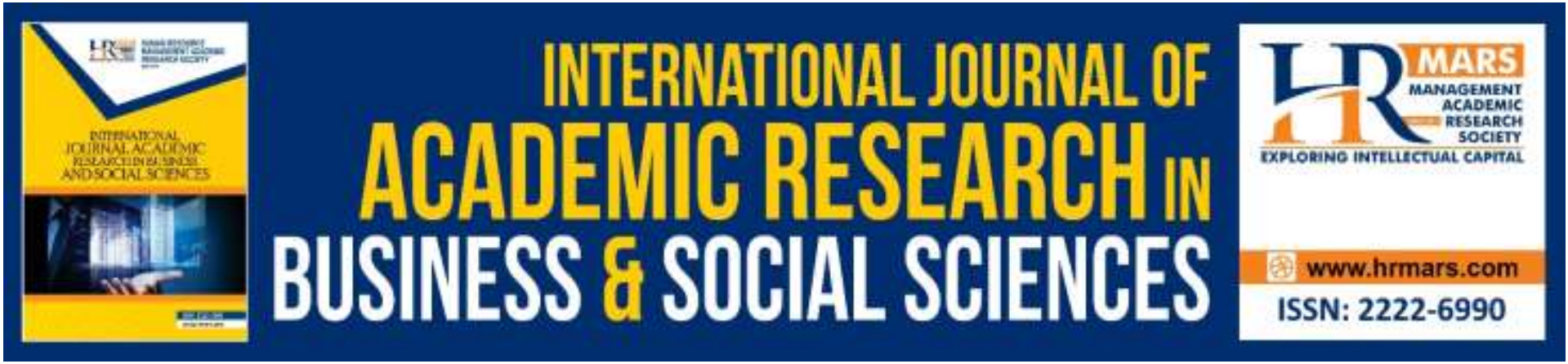

\title{
The Challenges of Organizational Culture on Ethical Decision Making in Malaysian Local Authorities
}

Nik Zalina Megat Muda and Maisarah Mohamed Saat

To Link this Article: http://dx.doi.org/10.6007/IJARBSS/v9-i7/6191

DOI: $10.6007 /$ IJARBSS/v9-i7/6191

Received: 02 May 2019, Revised: 17 June 2019, Accepted: 30 June 2019

Published Online: 03 July 2019

In-Text Citation: (Muda \& Saat, 2019)

To Cite this Article: Muda, N. Z. M., \& Saat, M. M. (2019). The Challenges of Organizational Culture on Ethical Decision Making in Malaysian Local Authorities. International Journal of Academic Research in Business and Social Sciences, 9(7), 923-932.

Copyright: (C) 2019 The Author(s)

Published by Human Resource Management Academic Research Society (www.hrmars.com)

This article is published under the Creative Commons Attribution (CC BY 4.0) license. Anyone may reproduce, distribute, translate and create derivative works of this article (for both commercial and non-commercial purposes), subject to full attribution to the original publication and authors. The full terms of this license may be seen at: http://creativecommons.org/licences/by/4.0/legalcode

\section{Vol. 9, No. 7, 2019, Pg. 923 - 932}

Full Terms \& Conditions of access and use can be found at http://hrmars.com/index.php/pages/detail/publication-ethics 


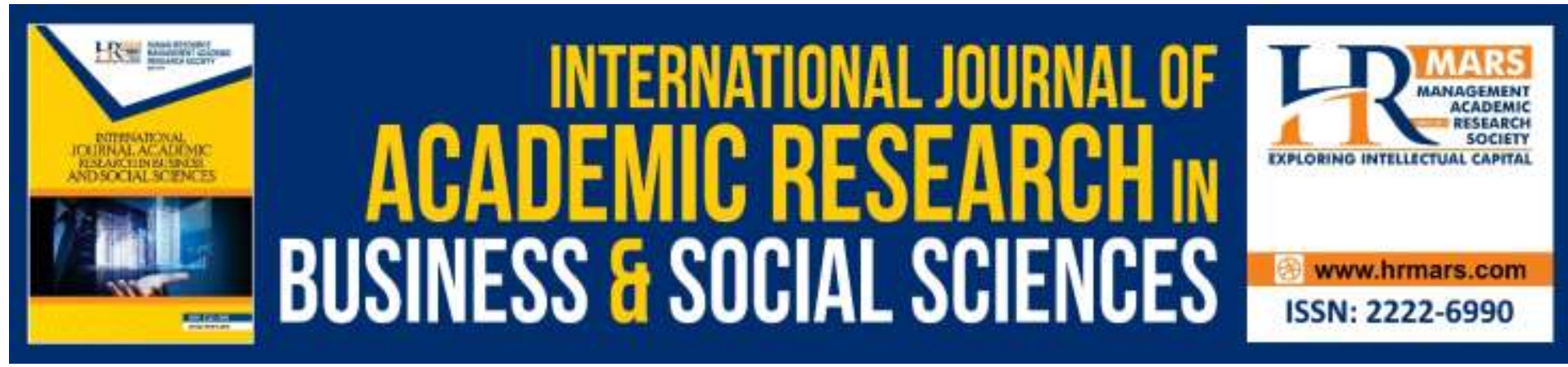

\title{
The Challenges of Organizational Culture on Ethical Decision Making in Malaysian Local Authorities
}

\author{
Nik Zalina Megat Muda and Maisarah Mohamed Saat \\ Azman Hashim International Business School, Universiti Teknologi Malaysia \\ Email: zalina@mpsj.gov.my, maisarahsaat@utm.my
}

\begin{abstract}
Ethical decision making is the most crucial action in an organisation as option chosen should not only consistent with values and principles, but also maintain the good reputation of the organisation. It is vital that decision makers go through a proper process of decision making which assist them to come to a coveted result. Based on the several unethical world scandals which involved abuse of power, manipulation of money in a government, false claims and corruption among the local authorities; these are found to be caused by improper or unethical decision making. Ironically, this unethical problem involves senior officials of the local authorities in Malaysia. Past research has suggested that the best solution to mitigate the risk of unethical behaviour which leads to unethical decision for the local authorities is to improvise the foundation which is enhancing the awareness and educational programs to promote ethical behaviour among the managers. This is hoped to increase their commitments to ethics and make it a culture and norm in their daily decision making. Keywords: Local Authority, Organizational Culture, Organizational Commitment, Ethical Decision Making
\end{abstract}

\section{Introduction}

Ethical decision making is the most crucial action in an organization as option chosen should not only consistent with values and principles, but also maintain the good reputation of the organization particularly the local authority. This is because decisions bring about good or bad effects. In the context of local authorities, the effect is immense as it involves public. Aside from taking the responsibilities in the arrangement of public facilities and infrastructure, networks, waste management, health administration and etc., local authorities are subjected to perform public services too. Annually, the financial allocation is taken from the total revenue collection such as assessment tax, license issue revenue, house renovation or premises and rental will be spent to prepare the public facilities. (Suhaiza et al., 2017). This is to show that ethical decision making is paramount. 


\section{Overview the Ethical Decision Making in Malaysia Local Authorities Ethical Decision Making}

Ethical decision making refers to the process of assessing and choosing between the alternative in a manner that is consistent with ethical principles. In making ethical decision, an organisation or management have to make assessment and disregard those unethical decisions as well as choosing the best alternative of ethical decision that is on par with the administration circular Guidelines for morning meeting management provision on, 1993. The objective of implementing this, is to have an immediate solution or so called "On the Spot" solution to be taken so that it can can detect all obstacles and enable immediate settlement action (www.mampu.goy.my). Ethical decision making has received attention from researchers who want to understand ethical behavior. The increase in the number of theoretical frameworks which has been proposed to reflect such behavior. Despite the notion, ethical decision making is very challenging as many other complex factors including cultural influences have been theorized as the key determinant of such behavior (Mustamil, 2010).

\section{Local Authorities}

The local authority or known as the Local Government is the third government in the Malaysian government hierarchy after the Federal government and the State government. As stated regarding the position of local government in Malaysia in the Federal Constitution. Pursuant to Article 4 and 5 of the Ninth Schedule of the Federal Constitution, all local authorities outside the Federal Territory directly under the exclusive jurisdiction of the State Government except the Federal Territory of Kuala Lumpur, Labuan and Putrajaya (Federation, 1963). Which means that the State Government has the power to control local authorities and to ensure their effectiveness and efficiency. Local Authorities is an organization that has the power and authorities to enforce an act to ensure the prosperity and sustainability of the people by carrying out their duty in planning, enforcing and control the planning well and serve with sincerity and fairness to the local community. These local government is a medium or intermediary between the state and the people (Suhaiza et al., 2017). The local authority is a body that responsible to manage the governance of an individual, created through its own legislation. Hence, the ethical decision making is one of the crucial aspect for an administrator in local authority as it reflects through the effects whether it is a positive or negative effects.

\section{Organizational Culture}

Organizational culture can influence the right decision and at the same time it can be considered as a central theme for the entire company as it explains and further elaborate the actions that need to be taken. Organizational culture also affects the decisions and actions of its employees by affecting their acceptance or rejection of a decision (Mustamil, 2010). Strong influence will change the organization to implement new decisions effectively through action. In order to create a conducive organizational culture, the attitude of the staff must be changes and eventually it will change the behaviour of the organizational members. Ethics is a common value system that contains ethics that influences employee behavior. Nowadays, stakeholders view the 
company or organization as living organisms, with their own minds and wants, so that organizational culture becomes Putama's concern (Aprilliani et al., 2014).

\section{Organizational Commitment}

Commitment in the organization refers to the a sense of affection by individuals or workers to the organization. They tend to behave well to keep the name and image of the organization. Organizational commitment is the emotional feeling of an organization (Lanza et al., 2013). The management will make thr best ethical decisions and comply with the rules and regulations set forth. Commitment is also one of the factors defined as acts and responsibilities that will influence the behavior within the organization. Aside from that, commitment is the belief in encouraging a manager to make the right decisions. Workers' understanding of the goals and objectives of the organization in line with the vision and mission will encourage them to commit and take part in contributing to the success of the organization (Bahrami et al., 2015).

\section{Issues of Ethical Decision Making in Local Autorities Scandal in Ethical Decision Making}

How well do the civil servants understand the requirement of ethical decision making has always been a question. The fall of an organization is due to the mistake in decision making such as the occurrence of a world economic scandal engraved in history and being a lesson to the world community. Among the famous events, the world-wide financial management scandals such as Enron, WorldCom Quest, Tyco, and Global Crossing in the United States involving fake financing while Tesco in the United Kingdom involved with unreasonable gains to be identified. In the context of Malaysia, among the among the scandals that have taken place and are warmly spoken by the Malaysian community namely the Port Klang Free Trade Zone (PKFZ), the Malaysian Airlines System (MAS) and Transmile Group Bhd. The scandal occurred due to the failure of ethical decision making due to personal interest and abuse of power (Boon et al., 2017).

\section{Perception on Corruption by Sector}

In 2017, according to a research on Major Public Sector Institutions which have conducted a survey on the people and their views on the issues of corruption from various influential groups and key institutions in their country. Globally, police and elected representatives (such as MPs, congresses, senators, etc.) are seen to be the most corrupt of $36 \%$, followed closely by government officials, businessmen and local government officials (Pring, 2017). However, local authorities is ranked fifth, which is something very worrying if no precautions and awareness are taken. 
Figure 3.1 : Graph below shows the rate of corruptions according to various sectors worldwide.

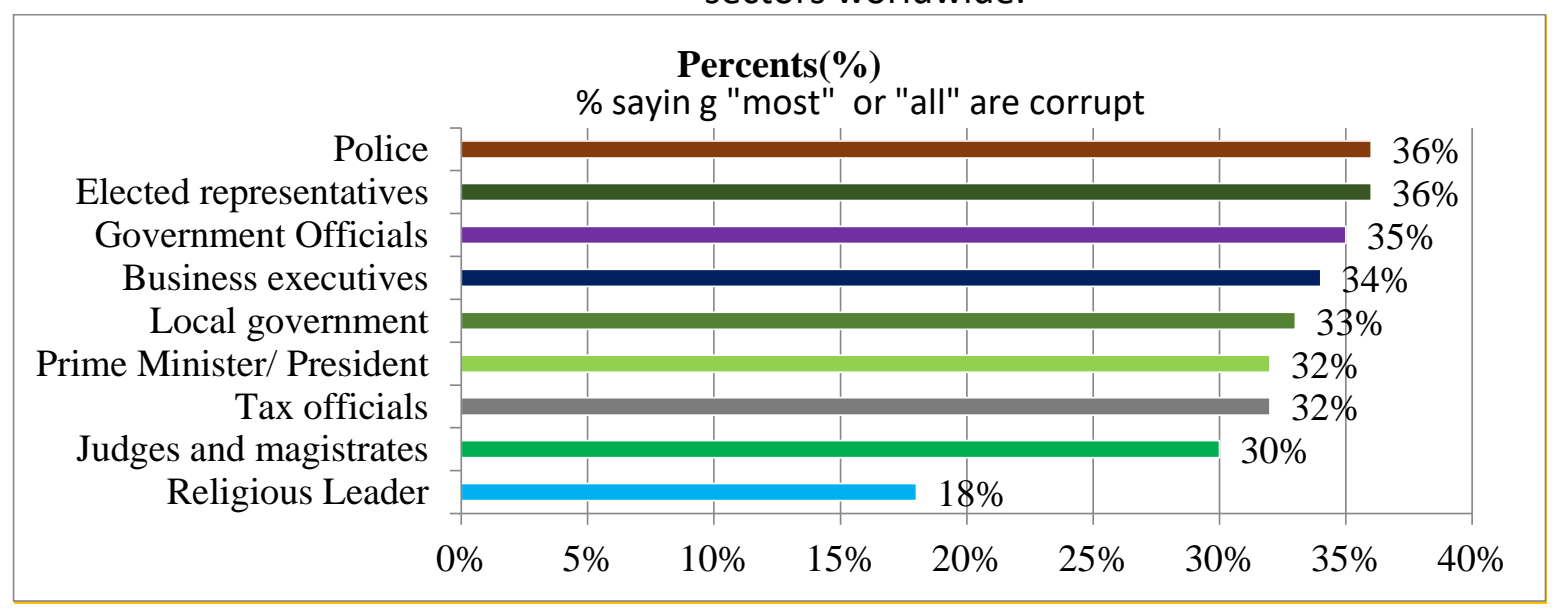

Sources: www.transparency.org.my, 2019

\section{Malaysian Anti Corruption Commission (MACC) Report}

According to the reports by Malaysian Anti Corruption Commission (MACC), there were concerns in the percentage of arrests to civil servants according to the service group found guilty of bribery. Does the increase give a bad idea about the integrity of civil servants or may require further research? In details, we can see the cause and what action needs to be taken by the agency. Based on the above graph, the number of arrests from professional and management groups has increased in 2013 up to 2018. However, the number decreased after the 2017 elections as the new government introduced leadership towards integrity and high-profile cases were struck like the 1MDB scandal, the case of SRC International Sdn. Bhd, a RM2.6 billion donation, Felda scandal and Sabah water. Based on these statistics, it is clear that the trends and cultures do not integrate into practice in the public sector, including in local authorities? 
Figure 3.2 : Graph below shows Total Offence of corruptions among the civil servants 2013-2017

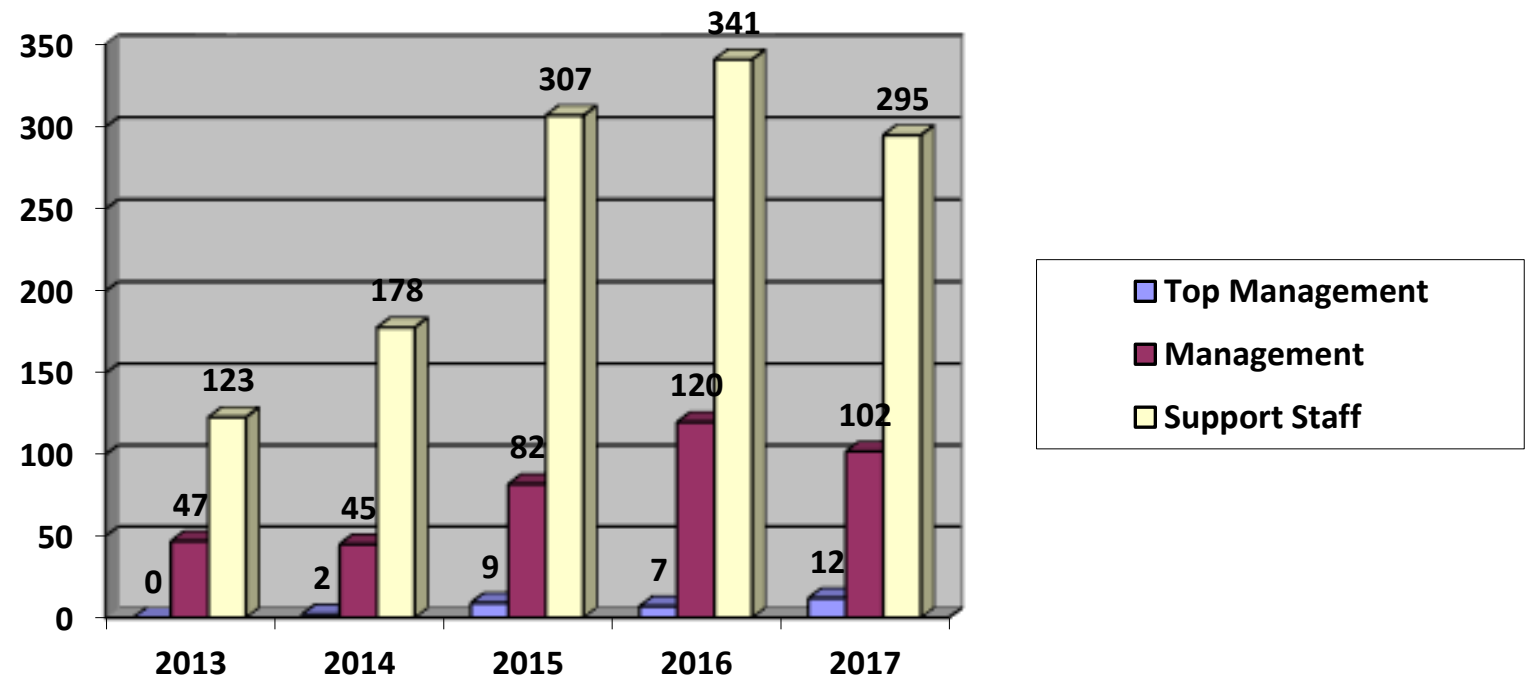

Sources : www.sprm.gov.my 2018

\section{Corruption Perception Index (CPI)}

The reports of Transparency International Malaysia (TI-M) in 2018 shows that Malaysia's position at 61 out of 180 countries is an increase compared to the position in 2017 which is 47 out of 180 countries in 2017. Despite the deterioration and decline in scores in 2018, there has been political developments especially in the region, particularly in Malaysia (47), Maldives (31), Pakistan (33) and India (41). Although Malaysia has made significant progress since the election in 2017, including the major arrest of corrupt officials, the country has conducted a continuous investigation into the 1Malaysia Development Berhad (1MDB) scandal estimated at over US $\$ 4.5$ billion and involving political leaders at the highest level of government ( www.trasparency.org.my, 2019).

Figure 3.3 : Graph below shows Corruption Perception Index (CPI)

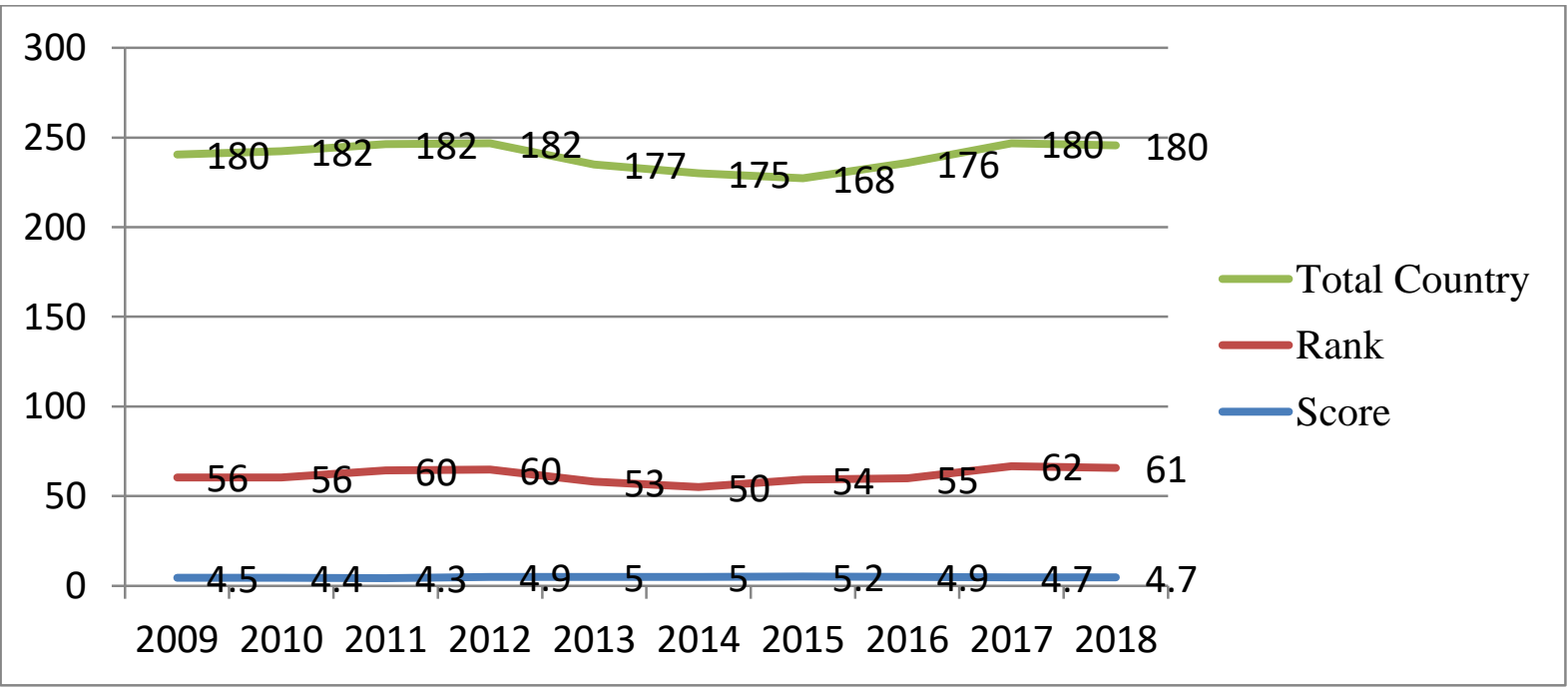


Souces: www.transparency.org.my, 2019

\section{Challenges of Ethical Decision Making The Councillor}

The councillor in Local Authority is selected by the state government to represent certain political party. Their appointment as Local Authority councillors is to perform tasks as a planner and decision maker in the administration of the council. The issues and roles of councillors sometimes lead to conflict in the implementation of a council policy and sometimes disagree with their political party policies which is influence by public community (Ngah et al., 2015). Differences in the educational background also affects the decision of the ethical decision making because it requires a high level of thinking and is competent with the relevant laws, acts and regulations including local government act 1976. Local government officers and councillors indicated that they are largely responsible and accountable to the state and federal government as well as the people they serve.

Conflict between policy makers occurs within the politico-administrative system (council, administration, mayor). Sometimes they are not familiar with the rules and regulations and this influence the internal policy and Standard of procedure (SOP) (Siti Nabiha 2010). The duration of the appointment is different as the duration of political party in power will determine their position as councilor. Frequency of switching among councillors at local authorities sometimes complicates their management and administration. Current political occasions give little path to local government to be changed to a completely decentralized level; or any expectation of more selfgovernance. Recentralisation instead of decentralization seems, by all accounts, to be the pattern in Malaysia and it is obvious that local government's supportability depends more on legislative issues as opposed to financial aspects (Nooi and Teik, 2011).

\section{Leadership}

Issues of the weaknesses in Local Authority usually becomes the cause the deterioration of a local authority image. The role of the leader in Local Authority in addressing the issue of corruption understanding among Local Authority staff is low compared to staff in other government departments. It can be proven by the evident in the study by Azmi in 2010, which only 60.5 percent of Local Authority staffs who expressed their opinion that using office allocation for self-interest corruption. Almost 40 percent of Local Authority staffs still consider the use of office provision for selfinterest is not an offense. The reports also concludes that the index score 6.76 is a rather worrying index (Azmi et al., 2010). Additionally, a charismatic and respected leader and eliminates the interest in mixed society such as conflict with the ability to mobilize people to work for the common good of the community. The ethical decision making process can be defined as a conscious and reasonable decision in adhering to professional ethics (Drahomira, 2017).

Recently, the administrative issues and weaknesses in unethical decision making in the civil service have been a widely debated in the mass media and electronic media. 
Even the issue of accountability and integrity have also received attention in the Local Authority. Although various initiatives and new initiatives have shown an increased accountability in service delivery to the community (Zakaria et al., 2011). The main role of leadership is Setting new direction and getting people along the right direction with charismatic and respected leader (C.chikeleze et. el 2017). The dilemma in decision making due to outdated procedures and laws causes them to take a discretionary approach that can be unethical decisions taken. The discretionary decisions made by leaders are inherently ethical because of the far-reaching and highstakes consequences these decisions may have for individuals internal and external to the leader's organization (Thiel et al., 2012).

\section{Dilemma}

Recognitions in the Trevino model (1986) have outlined the relationship of contemplations between morals, moral conduct, and factors influencing both. There is another component that influences moral issue, which is known as a contention of moral issues (Lee and Selart, 2014). Depending upon the circumstance, trust can either reinforce or debilitate the procedure of moral basic leadership. Without moral comprehension, it is inconceivable for an individual to settle on moral choices. In this way, the view of moral issues it self can be a significant factor influencing the dimension of good thinking. The decision-making process will constantly display ethical challenges to managers. We can lose someone's trust and undermine our own integrity (Alvani, 2016). A decision-making that that depends on cautious and reasonable arranging might be helpless. Also outlines one proposed solution for for the situation of adequacy and imagination in local government decision making that conflicting interests ought not be accursed as the hindrances of the effective working. Rather, they ought to be viewed as triggers or strains, which actuate connections between the entertainers of the procedure (Jalonen, 2014).

Therefore, the local authorities is a closed government administration and is the closest to the citizens. They have to face the pressure from the people to provide the best service, transparency and accountability. Other than that, local authorities had to face bigger obstacle caused by the increment of urbanisation, the population of education level and the growth of industrialisation of the country. (Kementerian Perumahan Dan Kerajaan Tempatan, 2003). Local authorities spent more time and money to achieve change and higher achievement through those new approachment in management (Amin Nikpor, 2017). Influence by stakeholder element that affects easily ethical dilemma, which is called a conflict of ethical problems (Cooper, 2015).

\section{Time}

Longer time taken in decision making can cause delays in resolving actions. The weakness of the management will disrupts the public's trust in the presentation of public services and the things that evolve around them. (Zulkifli et al., 2016). The function of the local government in delivering services to the people effectively and best and as government are the closest to the people, especially in refering to the policy decision stages implemented (Osman et al., 2014). The success of an 
organization depends on the accuracy of decision making in the right time and vice versa.

The weakness of the management will disrupts the public's trust in the presentation of public services and the things that evolve around them. (Zulkifli et al., 2016). Time taken to solve the issues can Involve the third parties like state \& federal (disagreement). The Budget Issues will be take long time because afew sop and prosedur to approve the budget from the state. The public will not satisfied with this issues and will Lost trust from the public. The complaint will Increase and the end result is the public trust and the public satisfaction

\section{Conclusion}

Ethical decision making is one of the important thing as an administrator in a local authority because each decision taken will lead to good or bad effects. Aside from taking the responsibilities in the arrangement of public facilities and infrastructure, networks, waste management, health administration and etc. local authorities play a significant role in ensuring the achieving of national aspirations. Errors in decision making can have detrimental impact on the community, especially in the terms of customer trust and dissatisfaction. The success of an organisation depends on the decisions made by the managers; it must not only be ethical but timey - that is the challenge. These challenges will have to be faced by the local authorities in meeting the expectation from public.

\section{Acknowledgement}

I appreciate the financial support by Pejabat Setiausaha Kerajaan Selangor (SUK), which makes it possible for me to complete my studies. Finally, I want to thank my family for their support and understanding.

\section{Corresponding Author}

Nik Zalina Megat Muda

Azman Hashim International Business School

Block T08, Universiti Teknologi Malaysia,

81310 Johor Bahru. Johor

Email: zalina@mpsj.gov.my

\section{References}

Alvani, P. S. M. (2016) 'Ethical Decision Making in Issues Management', IOSR Journal of Humanities and Social Science, 21(07), pp. 34-39.

Nikpor, A. (2017) 'INTERNATIONAL JOURNAL OF ORGANIZATIONAL LEADERSHIP The impact of organizational culture on organizational performance: The mediating role of employee's organizational commitment', International Journal of Organizational Leadership, 6, pp. 65-72.

Jalonen, H. (2014) 'Managing complexity in local governments' decision making', (November).

Lee, W. S. and Selart, M. (2014) 'The influence of emotions on trust in ethical decision making', Problems and Perspectives in Management, 12(4), pp. 573- 
580.

Ngah, K., Penyelidikan, P., Dan, D., Antarabangsa, K., Zakaria, Z., Noordin, N. and Mustaffa, J. (2015) 'Decision-Making Model at Local Government Level: A New Proposed for Majlis Perbandaran Kuantan', ISSN, 6(1), pp. 2222-1700.

Nooi, P. S. and Teik, G. C. (2011) 'Century: Challenge and Prospect”, 12-13 December 2011, Xiamen University 1', China-ASEAN Cooperation in the 21st Century: Challenge and Prospect, (December), pp. 12-13.

Osman, M. M., Bachok, S., Bakri, N. I. M. and Harun, N. Z. (2014) 'Government

Thiel, C. E., Bagdasarov, Z., Harkrider, L., Johnson, J. F. and Mumford, M. D. (2012) 'Leader Ethical Decision-Making in Organizations: Strategies for Sensemaking', Journal of Business Ethics, 107(1), pp. 49-64.

Trevino, L. K. (1986) 'Ethical Decision Making in Organizations: A Person-Situation Interactionist Model.', Academy of Management Review, 11(3), pp. 601-617.

Treviño, L. K., Weaver, G. R. and Reynolds, S. J. (2006) Behavioral Ethics in Organizations : A Review.

Zulkifli, N., Rahman, S., Nurudin, S. M., Hamik, S. A., Mohamed, A. S. P. and Hashim, R. (2016) 'Managing Public Perception towards Local Government Administration', International Journal of Public Policy and Administration Research, 3(2), pp. 14-20. 